The original solution contained $0.85 \mathrm{cc}$. of concentrated nitric acid to every ro cc. of solution.

The rate at which bismuth was precipitated was determined with $20 \mathrm{cc}$. of the solution containing 0.4650 gram of bismuth in the presence of $1.20 \mathrm{cc}$. of concentrated nitric acid.

\begin{tabular}{|c|c|c|}
\hline Time. & Bismuth taken. & Bismuth found. \\
\hline $\mathrm{I}$ & 0.4650 & 0.0510 \\
\hline 3 & 0.4650 & 0.1100 \\
\hline 5 & 0.4650 & 0.2263 \\
\hline 7 & 0.4650 & 0.3244 \\
\hline io & 0.4650 & 0.3622 \\
\hline I5 & 0.4650 & 0.4027 \\
\hline 20 & 0.4650 & 0.4528 \\
\hline 25 Bismuth all out. & 0.4650 & 0.4645 \\
\hline
\end{tabular}

During the electrolysis, what was taken to be the peroxide always collected on the anode, but, as in other cases, it always dissolved without any trouble before the determination was complete. The smaller the amount of acid present the more likely this was to form. In one or two cases small amounts of the oxide did not dissolve from the anode where it was rough but the amount was not weighable. A black precipitate of bismuth frequently collected under the anode on the mercury but as the electrolysis proceeded this amalgamated without difficulty. It was possible to precipitate, by means of this method, 0.4659 gram of bismuth in 25 minutes. Taking it all in all, this is as good a method as we have for the determination of bismuth.

\title{
Summary.
}

(1) The apparatus is as simple as any electrolytic apparatus made.

(2) The deposition by this method is nearly as rapid as by the rotating anode and mercury cathode.

(3) The results are as accurate as those obtained by other methods where mercury is used as the cathode.

LNIVERSITY OF ARIzONA, TuCson.

\section{THE ESTIMATION OF SMALL QUANTITIES OF NITROGEN BY PELOUZE'S REACTION.}

BY A. T, DAVENPORT.

Received July 2, 1910.

During some recent work, in which the writer was engaged, it became necessary to estimate very small quantities of nitrogen occurring in the form of nitrates. Various methods for the determination were tried, but none of those which are ordinarily satisfactory, quite supplied the needs in this particular case. Among all the methods tried, that which most nearly fulfilled all the conditions imposed was one in which the following reaction, originally employed by Pelouze, was used: 


$$
6 \mathrm{FeCl}_{2}+2 \mathrm{KNO}_{3}+8 \mathrm{HCl}=3 \mathrm{Fe}_{2} \mathrm{Cl}_{6}+2 \mathrm{KCl}+{ }_{4} \mathrm{H}_{2} \mathrm{O}+2 \mathrm{NO} \text {. }
$$

More than fifteen different forms of apparatus, employing as many different methods of procedure, have been designed for the analysis of nitrates by the ferrous chloride reduction method. This variety in methods for conducting the analysis is evidence that it is difficult to get a process universally satisfactory, and also evidence that the determination is based on good fundamental principles, and worthy of effort spent to perfect the mechanical operation.

The development of methods has followed two distinct lines. In one direction, speed and ease of manipulation have been sacrificed for accuracy-this trend is illustrated in the extreme by Schlösing's intricate but accurate method of analysis. In the other direction, accuracy has been more or less neglected in an effort to eliminate all awkward operations and time-killing refinements, and here a method devised by $P$. Wagner easily leads the rest in so far as simplicity is concerned. Wagner collects the evolved nitric oxide over water in graduated cylinders, which are directly compared with a similar cylinder containing nitric oxide from a weighed amount of pure potassium nitrate, and kept, as nearly as possible, under the same conditions. The most generally used of the more refined methods in which high accuracy is maintained is that one worked out by Schultze, and modified by Tiemann. In SchultzeTiemann's apparatus the liberated nitric oxide is collected in a jacketed burette over caustic soda solution, and the volume corrected to standard conditions according to the regular procedure in gas analysis. In the method to be described below, an effort has been made to combine the good points in Wagner's, and the Schultze-Tiemann methods, and to eliminate as many as possible of the defects.

Some of the most important features found in the new method are: measurement of the gas volume over caustic soda solution in a jacketed burette graduated to $\mathrm{I} / 20 \mathrm{cc}$, as in the Schultze-Tiemann method, thereby insuring a thorough washing of the gas, and protecting it against sudden and local heating, or cooling, as may occur in Wagner's method. Correction of the gas volume by comparison with a standard volume contained in another burette under identical physical conditions which does away with lengthy calculations employed in the method of Schultze and Tiemann. Besides these features, the apparatus is so designed that it does away with several of the awkward operations belonging to the Schultze-Tiemann method, and thereby, approaches the simplicity of Wagner's procedure.

A description of the apparatus and method of operation is given below.

\section{Details of Operation.}

$C$ and $F$ are nearly filled with $25^{-27}$ per cent. caustic soda solution. By alternately opening pinchcocks $h$ and $k$ the caustic in $F$ is allowed 
to replace the air in $E$ and $l$. The stopcocks $c c$ are opened and with a slight vacuum, the burettes are filled with caustic solution from $F$.

Next, 5o cc. of a nitrate solution, of a strength suitable to the capacity

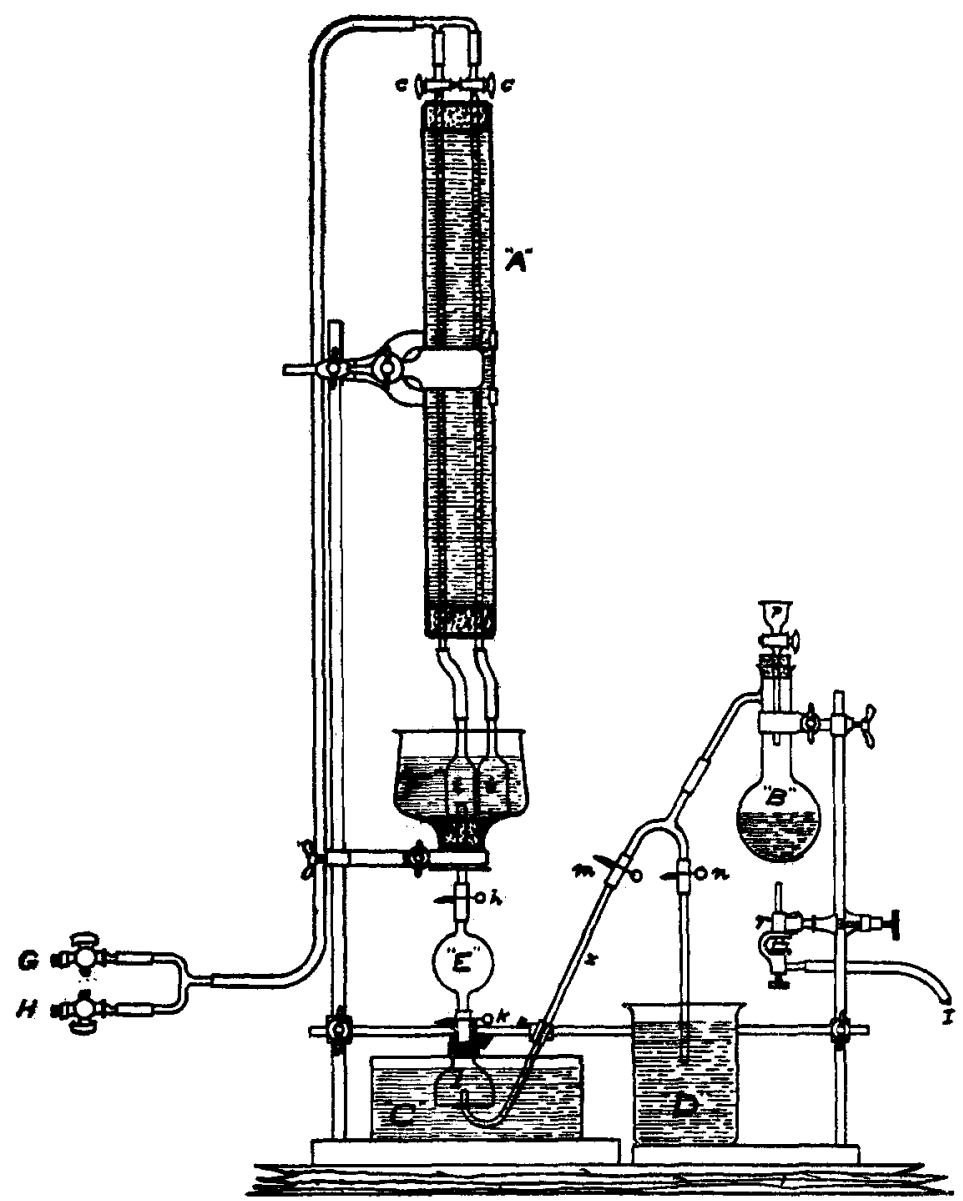

$A$ - Water jacket containing two burettes graduated to $I / 20 \mathrm{cc}$.

$B$-Distilling flask in which the nitrates are decomposed.

$C$-Glass dish containing caustic soda solution.

$D$-Beaker of water to act as a seal.

$E$-Glass bulb filled with caustic soda for washing and cooling the nitric oxide.

$F$-Glass basin containin caustic soda from which the burettes are filled.

$G$-Compressed air.

$H$-Vactum.

I-Gas.

$t, t$ and $l-$ Glass bells for collecting gas.

$p-A$ dropping funnel having a capil ary stem 
of the burettes, is placed in the flask $B$. The pinchcock $n$ is opened, and the gas burner, which is on a movable support $r$, is swung under the flask. When the liquid begins to boil, the flame is swung from under the flask, and $n$ closed while $m$ is opened to allow caustic from $C$ to rise by suction in the outlet tube $x$, as far as the fork. Then $m$ is closed, and the heating of $B$ continued. As soon as pressure begins to derelop in the flask, as shown by the inflation of the rubber connections, $n$ is opened and all the air in $B$ boiled out through the water in $D$.

Next, the flame is removed from under the flask, and $n$ closed. As soon as a vacuum begins to form, $15 \mathrm{cc}$. each of concentrated ferrous chloride solution, and concentrated hydrochloric acid are introduced through the dropping funnel $p$, care being taken to close the stopcock before any air can rush through. The heating of $B$ is renewed, and as soon as a slight pressure forms, the pinchcocks $m$ and $k$ are opened, when the liberated nitric oxide passes over and collects in $E$, where it is cooled and washed. After all the gas has passed over as shown by a cessation of bubbles, a partial vacuum is again formed in the flask, and the small amount of gas dissolved in the excess of ferrous chloride is extracted by the suction-upon reheating this residue of gas is driven over into $F$.

Next, one of the glass bells $t$ is placed over the outlet from $E$, and pinchcock $k$ closed, and $h$ opened, when the gas passes up into the burette.

After standing for three minutes, the volume of the gas is noted. A standard nitrate solution is made by dissolving I gram of pure potassium nitrate in $250 \mathrm{cc}$. of distilled water. Under the conditions of the test one cc. of the standard solution gives practically $\mathrm{I} c \mathrm{c}$. of gas, so in case we have Io $\mathrm{cc}$. of gas in the above operation, $10 \mathrm{cc}$. of the standard solution are decomposed according to the above procedure, and the gas passed into the other burette for direct comparison with the neighboring gas volume.

At the completion of an analysis the stopcock $c$ is opened, and compressed air carefully bubbled throtgh $F$, when the burette is quickly swept free from nitric oxide.

A determination can be made in ten minutes, and the results of consecutive analyses agree very well as can be seen from the following table:

Analysis showed---

Io cc. of solution to be equivalent to

$\begin{array}{lc}\text { 10. } 55 \mathrm{cc} \text {. of } \mathrm{NO} \text {, or } 8.8 \mathrm{I} \mathrm{cc} \text {. of } \mathrm{NO} \text { at } \mathrm{O}^{\circ} \text { and } 760 \mathrm{~mm} \text {. } \\ \text { 10. } 60 & 8.85 \\ \text { 10 } 60 & 8.85 \\ \text { 10.50 } & 8.77 \\ \text { 10.65 } & 8.89 \\ \text { 10.60 } & 8.85 \\ \text { 10.70 } & 8.93 \\ \text { 10. } 65 & 8.89\end{array}$

I0.6I Average 
Solutions of pure potassium nitrate were used, I gram of potassium nitrate in $250 \mathrm{cc}$. of water at $20^{\circ}$. Ten cubic centimeters of this solution are equivalent to $8.86 \mathrm{cc}$. of nitric oxide at $0^{\circ}$ and $760 \mathrm{~mm}$.

Considering the average volume $10.6 \mathrm{I} \mathrm{cc}$. of $\mathrm{NO}$ as being equivalent to $8.86 \mathrm{cc}$. of $\mathrm{NO}$ at $\mathrm{o}^{\circ}$ and $760 \mathrm{~mm}$. the factor 0.835 was deduced with which the column of corrected volumes was obtained.

If there is a doubt as to whether the nitrate used for standard is pure, or whether all the gas is being driven over it is a simple matter to transfer the gas to a Hempel burette, and measure it under atmospheric pressure.

The direct comparison of gas volumes not only simplifies calculations, but also introduces the safeguards of a duplicate test against error.

The method of analysis has been in use at this laboratory for more than a year, and the article is published with permission of the E. I. du Pont de Nemours Powder Co.

EXPERTMENTAL STATION,

E. I. DU PONT de Nemours Powder Co.

WILMINGTON, DELAWARE.

\section{THE ANALYSIS OF TIN-ANTIMONY ALLOYS.}

BY LEROY W. MCCAY.

Received August 9, 1930.

The fact that hydrogen sulphide precipitates the antimony only from a dilute hydrofluoric acid solution containing tin in the higher and antimony in the lower stage of oxidation serves as an excellent means for the quantitative separation of these two elements. ${ }^{1}$ If the solution be a hydrochloric or sulphuric acid one, the addition of hydrofluoric acid converts the metals into their fluorides, and the solution can then be diluted indefinitely without becoming turbid. The mixture of stannic sulphide, antimonious and antimonic sulphides and free sulphur obtained in the regular course of analysis was, until recently, ${ }^{2}$ always dissolved in warm concentrated hydrochloric acid in a small platinum dish, hydrofluoric acid added, the solution filtered into a large platinum dish holding about $500 \mathrm{cc}$, and from the diluted solution the antimony precipitated in the cold with hydrogen sulphide as antimonious sulphide. The objection, however, to this method of dissolving the tin and antimony sulphides is that the accompanying sulphur, along with that which separates from the pentasulphide, forms, or seems to form, a protecting coating about some of the antimonious sulphide, so that it remains unattacked by the hydrochloric acid. Even after two extractions with the warm, concentrated acid antimony can generally be detected in the sulphur.

1 This Journal, 3 I, 373 (Igo9).

2 The neutralization of the solution with sodium hydroxide and the addition to it, after introducing the hydrofluoric acid, of an excess of sodium acetate has proved unnecessary. See original paper, loc. cit. 